\title{
Neutron Diffraction Study on the Magnetic Structure of $\mathrm{Pr}_{6} \mathrm{Fe}_{13} \mathrm{Sn}$
}

\author{
Suharyana $^{1^{*}}$, J. M. Cadogan ${ }^{2}$ and Agitta Rianaris ${ }^{1}$ \\ ${ }^{1}$ Physics Department, Faculty of Mathematics and Natural Sciences, \\ Sebelas Maret University Surakarta 57126, Indonesia \\ ${ }^{2}$ School of Physics, The University of New South Wales, Kensington NSW 2033, Australia
}

\section{ARTICLE INFO}

\section{Article history:}

Received 20 November 2009

Received in revised form 3 April 2010

Accepted 20 April 2010

\section{Keywords:}

Rare-earth intermetallics

Neutron diffraction

Antiferromagnetic

$\mathrm{Pr}_{6} \mathrm{Fe}_{13} \mathrm{Sn}$

\begin{abstract}
A B S T R A C T
We have successfully prepared a $\mathrm{Pr}_{6} \mathrm{Fe}_{13} \mathrm{Sn}$ sample by employing argon arc melting. The crystal structure of the sample has been examined by an x-ray diffraction. The x-ray pattern reveals that the sample crystallize in the tetragonal $\mathrm{Nd}_{6} \mathrm{Fe}_{13} \mathrm{Si}$ structure type with space group $I 4 / \mathrm{mcm}$. Neutron diffraction at $150 \mathrm{~K}$ performed on a powder sample shows a collinear antiferromagnetic ordering of the Fe and Pr sublattices with the wave vector $(0,0,1)$ and an $I_{\mathrm{p}}$ type magnetic lattice with anti-centering translation. The main axis of antiferromagnetism is restricted to the $\left(\begin{array}{lll}0 & 0 & 1\end{array}\right)$ plane. The average refined Fe moments at $150 \mathrm{~K}$ is $(2.0 \pm 0.4) \mu_{\mathrm{B}}$ whereas the Pr moments are $(2.1 \pm 0.4)$ and $(1.9 \pm 0.4) \mu_{\mathrm{B}}$ for the $8 f$ and $16 \mathrm{l}$ sites, respectively
\end{abstract}

(C) 2010 Atom Indonesia. All rights reserved

\section{INTRODUCTION}

Compounds with a chemical formula $\mathrm{R}_{6} \mathrm{Fe}_{13} \mathrm{X}$ ( $\mathrm{R}=$ light rare-earth $\mathrm{Pr}$ and $\mathrm{Nd} ; \mathrm{X}=$ nonmetal $\mathrm{Cu}, \mathrm{Ag}$, $\mathrm{Au}, \mathrm{AL}, \mathrm{Si}, \mathrm{Ge}, \mathrm{Sn}$ ) are frequently obtained when transition metal rich Fe-based alloys are used as starting materials for $\mathrm{Nd}_{2} \mathrm{Fe}_{14} \mathrm{~B}$ - or $\mathrm{Pr}_{2} \mathrm{Fe}_{14} \mathrm{~B}$ - type permanent magnets. It is believed that the role of the second phase of $\mathrm{R}_{6} \mathrm{Fe}_{13} \mathrm{X}$-type may enhance the coercivity in $\mathrm{Nd}_{2} \mathrm{Fe}_{14} \mathrm{~B}$-type permanent magnets with an $\mathrm{X}$ element addition. Since the $\mathrm{Nd}_{2} \mathrm{Fe}_{14} \mathrm{~B}$ type permanent is an important technology material, it is of special interest to study the structural and magnetic properties of these second phase compounds.

The crystal structure of the compounds of the composition $\mathrm{R}_{6} \mathrm{Fe}_{13-\mathrm{x}} \mathrm{X}_{1+\mathrm{x}}$ was unrevealed in 1985 by Siechevich et al. [1]. Particularly they have shown that compound $\mathrm{La}_{6} \mathrm{Co}_{11} \mathrm{Ga}_{3}$ orders in a tetragonal structure with space group $I 4 / \mathrm{mcm}$. Later on, Allemand et al. [2] have shown that $\mathrm{Nd}_{6} \mathrm{Fe}_{13} \mathrm{Si}$ crystallizes as an ordered variant of this compound. The crystal structure is rather complicated with four different Fe sites, namely $16 k, 16 l_{1}, 16 l_{2}$, and $4 d$, two Nd nonequivalent sites, $8 f$ and $16 l$, and one $\mathrm{Si}$ site $4 a$, forming a naturally layered atomic arrangement. The $\mathrm{R}$ atoms, especially those at the $16 l$ site, have mainly other $\mathrm{R}$ atoms as nearest neighbors. Consequently, in these compounds the $4 f-4 f$ interaction, which is normally much smaller

\footnotetext{
Corresponding author.

E-mail address: shry@mipa.uns.ac.id (Suharyana)
}

than the $4 f-3 d$ and $3 d-3 d$ interaction, might be of importance [3].

A strong debate about the magnetic properties of $\mathrm{R}_{6} \mathrm{Fe}_{13} \mathrm{X}$ has arisen. Claims about ferromagnetism [4], ferromagnetism with compensation point [5], and antiferromagnetism [6] have been made. This controversion has prompted us to prepare six $\mathrm{R}_{6} \mathrm{Fe}_{13} \mathrm{X}$ compounds $(\mathrm{R}=\mathrm{Pr}$ and $\mathrm{Nd} ; \mathrm{X}=\mathrm{Si}, \mathrm{Ge}$ and $\mathrm{Sn}$ ) single phase as far as possible and to reexamine their magnetic behavior. The magnetic properties of the compounds our investigated by employing $\mathrm{Cu}-\mathrm{K} \alpha \mathrm{X}$-ray powder diffraction, ${ }^{57} \mathrm{Fe}$ Mössbauer at temperatures in the range 295 - $500 \mathrm{~K}$ using a standard transmission spectrometer equipped with an Austin Science VF-1000 vacuum furnace. The source was ${ }^{57} \mathrm{Co}$ embeded in a Rh matrix. Also we employed a thermogravimetric analyzer (TGA) in a small magnetic field gradient using a Perkin Elmer TGA-7. AC-susceptibility was measured in a LakeShore Closed-cycle suseptometer at $137 \mathrm{~Hz}$. Nèel temperatures were determined by differential scanning calorimetry (DSC) on a Perkin-Elmer DSC-7, using the heat capacity peak at $\mathrm{T}_{\mathrm{N}}$ to signal ordering. We have shown that the compounds order antiferromagnetically at room temperature [7].

It should be noted that neutron diffraction experiment on $\mathrm{Pr}_{6} \mathrm{Fe}_{13} \mathrm{Sn}$ performed at temperature $1.5 \mathrm{~K}$ was reported [8]. They reported the $\mathrm{R}$ atom at the $16 \mathrm{l}$ site is weakly magnetic and its refined magnetic moment at room temperature is almost zero. Here, we present our neutron diffraction study 
of $\mathrm{Pr}_{6} \mathrm{Fe}_{13} \mathrm{Sn}$ compound in order to reexamine the paper of Schobinger-Papamentallos et al [8]. Our data was collected at $150 \mathrm{~K}$ and analyzed using GSAS [9].

This paper is organized as follows. First we describe experimental details of our sample preparation and measurement techniques. Next, we explain the successive experimental results. Finally, the main conclusions are presented.

\section{EXPERIMENTAL METHODS}

The $\mathrm{Pr}_{6} \mathrm{Fe}_{13}$ Sn sample, with a weight of $\sim 5 \mathrm{~g}$, was prepared from high purity materials of at least 99.9\% purity by arc melting in an atmosphere of purified argon. After melting, the ingot was wrapped in Ta foil, sealed in a sealed quartz tube under a partial pressure of purified argon at $973 \mathrm{~K}$ for one week. After annealing, the tube was quenched in water. Samples for x-ray and neutron diffraction experiments were prepared by crushing the resultant alloys under acetone using a mortar and pestle. The x-ray diffraction pattern was obtained on a SIEMENS D5000 diffractometer. $\mathrm{Cu}-\mathrm{K} \alpha$ was used. The step increment in $2 \theta$ was $0.05^{\circ}$ and the $2 \theta$ scanning speed was $0.5^{\circ}$ per minute. The pattern was collected in the $2 \theta$ region $25^{\circ}-60^{\circ}$. Constant wavelength neutron diffraction experiment on the $\mathrm{Pr}_{6} \mathrm{Fe}_{13} \mathrm{Sn}$ polycrystalline powder sample was performed at the Berlin Neutron Scattering Centre, Hahn-Meitner Institute in Berlin. The data were collected on the high resolution diffractometer of E9 $(\lambda=1.58313 \AA)$ at temperature $150 \mathrm{~K}$. The step increment in $2 \theta$ was $0.1^{\circ}$ and the data were collected in the $2 \theta$ region $3-156^{\circ}$. The pattern was corrected for absorption and evaluated by means of the Rietveld method using GSAS program.

\section{RESULTS AND DISCUSSION}

In Fig. 1 we display the $x$-ray diffraction patterns of $\mathrm{Pr}_{6} \mathrm{Fe}_{13} \mathrm{Sn}$ randomly oriented powder samples. Analyses of the $\mathrm{x}$-ray pattern was accomplished via the Rietveld method using the computer code GSAS. The refinement process of the Rietveld method requires a set of initial crystal parameter values and a correct space group. We used the atomic positions and lattice constants of $\mathrm{Nd}_{6} \mathrm{Fe}_{13} \mathrm{Sn}$ proposed by Allemand et al. [2] to start the refinement. It can be seen on the figure the theoretical (solid lines) pattern agree well with the observed (dots) pattern. The $\mathrm{R}$ factors, namely $\mathrm{R}_{\mathrm{p}}=1.50, \mathrm{R}_{\mathrm{wp}}=1.97$ and $\chi^{2}=7.8$, are satisfactory. Furthermore, no observed peaks unaccounted for and no extra miss fit peaks implying that the crystallographic structures of the samples confirm the $\mathrm{Pr}_{6} \mathrm{Fe}_{13} \mathrm{Sn}$ structure types reported previously by Allemand et al. [2]. In other words, the sample is virtually single-phase. The final refined lattice constants of $\mathrm{Pr}_{6} \mathrm{Fe}_{13} \mathrm{Sn}$ are $a=8.0914(8) \AA$ and $c=23.4687(4) \AA$ whereas the atomic positions and are presented in Table 1 . Numbers in parentheses are experimental errors.

Table 1. Refined atomic positions of $\mathrm{Pr}_{6} \mathrm{Fe}_{13} \mathrm{Sn}$ deduced from $\mathrm{x}$ ray diffraction data.

\begin{tabular}{|l|l|l|l|l|}
\hline atom & site & \multicolumn{1}{c|}{$\mathrm{x}$} & \multicolumn{1}{c|}{$\mathrm{y}$} & $\mathrm{z}$ \\
\hline $\mathrm{Nd}-1$ & $8 f$ & 0 & 0 & $0.1072(8)$ \\
\hline $\mathrm{Nd}-2$ & $16 l$ & $0.1605(9)$ & $0.6590(8)$ & $0.1862(7)$ \\
\hline $\mathrm{Fe}-1$ & $16 l_{1}$ & $0.1725(8)$ & $0.6815(7)$ & $0.0575(7)$ \\
\hline $\mathrm{Fe}-2$ & $16 l_{2}$ & $0.3811(8)$ & $0.8823(7)$ & $0.0946(7)$ \\
\hline $\mathrm{Fe}-3$ & $16 k$ & $0.0621(9)$ & $0.2042(8)$ & 0 \\
\hline $\mathrm{Fe}-4$ & $4 d$ & 0 & 0.5 & 0 \\
\hline Sn & $4 a$ & 0 & 0 & 0.25 \\
\hline
\end{tabular}

The magnetic structure of $\operatorname{Pr}_{6} \mathrm{Fe}_{13} \mathrm{Sn}$ has been investigated using powder neutron diffraction by Schobinger-Papamantellos et al. [11]. The magnetic unit cell of $\mathrm{Pr}_{6} \mathrm{Fe}_{13} \mathrm{Sn}$ is modeled as collinear moments of six ferromagnetic blocks. Each ferromagnetic block is embedded between two successive $S n$ layers perpendicular to the $z$ axis located at $z=0.25$ and 0.75 . The magnetic moments in these ferromagnetic blocks alter their sign collectively when going to the next blocks along the $z$ axis. As shown in Fig. 2 a model of magnetic structure of $\operatorname{Pr}_{6} \mathrm{Fe}_{13} \mathrm{Sn}$ due to [11] was displayed.

Neutron diffraction pattern of the polycrystalline powder $\operatorname{Pr}_{6} \mathrm{Fe}_{13} \mathrm{Sn}$ sample collected at temperature $150 \mathrm{~K}$ is shown in Fig. 3. The most important feature of the patterns is the appearance of a $\left(\begin{array}{lll}0 & 0 & 1\end{array}\right)$ peak located at $2 \theta=3.4^{\circ}$. Since the diffraction condition for the space group $I 4 / \mathrm{mcm}$ is $h+k+l=2 n$, the occurrence of the (llll $\left.\begin{array}{lll}0 & 1\end{array}\right)$ peak indicates that the magnetic ordering of $\mathrm{Pr}_{6} \mathrm{Fe}_{13} \mathrm{Sn}$ is antiferromagnetic. Furthermore, the magnetic lattice of $\mathrm{Pr}_{6} \mathrm{Fe}_{13} \mathrm{Sn}$ is $I_{\mathrm{p}}$ with a wave vector $(0,0,1)$. Thus, all $\mathrm{Fe}$ and $\mathrm{Pr}$ moments related by the $I$ translation $+(1 / 2,1 / 2,1 / 2)$ are antiparallel. It should be noted that with the exception of the $\left(\begin{array}{lll}0 & 0 & 1\end{array}\right)$ peak, the other magnetic contributions are difficult to distinguish from the nuclear reflections due overlap. This is made the data analysis is more difficult and the refined magnetic moment values are imprecise.

Following Opechowski and Guccione [10], there are sixteen magnetic space groups in the family of the crystallographic $I 4 / \mathrm{mcm}$ space group. They are presented in Table 2. 
Table 2. Magnetic space group in the family of the crystallographic $I 4 / \mathrm{mcm}$ space group [10]

\begin{tabular}{l|l}
\hline \multicolumn{1}{c|}{$\mathrm{A}$} & \multicolumn{1}{c}{$\mathrm{B}$} \\
\hline$I 4 / m c m$ & $I_{\mathrm{p}} 4 / m c m$ \\
$I 4 / m^{\prime} c m$ & $I_{\mathrm{p}} 4 / m^{\prime} c m$ \\
$I 4^{\prime} / m c^{\prime} m$ & $I_{\mathrm{p}} 4 ' / m c^{\prime} m$ \\
$I 4^{\prime} / m c m^{\prime}$ & $I_{\mathrm{p}} 4^{\prime} / m c m^{\prime}$ \\
$I 4^{\prime} / m^{\prime} c^{\prime} m$ & $I_{\mathrm{p}} 4 / m^{\prime} c^{\prime} m$ \\
$I 4 / m c^{\prime} m^{\prime}$ & $I_{\mathrm{p}} 4 / m c^{\prime} m^{\prime}$ \\
$I 4 ' / m^{\prime} c m^{\prime}$ & $I_{\mathrm{p}} 4 / m^{\prime} c m^{\prime}$ \\
$I 4 / m^{\prime} c^{\prime} m^{\prime}$ & $I_{\mathrm{p}} 4 / m^{\prime} c^{\prime} m^{\prime}$ \\
\hline
\end{tabular}

The magnetic space groups in column A can be ruled out immediately since they do not comprise $I_{\mathrm{p}}$. Furthermore, the Pr-1 atom at the Wyckoff position $8 f$ has a point symmetry group 4 . The magnetic space group cannot have a 4' component since the 4' symmetry is not an admissible magnetic point group. Thus, four of the eight possible magnetic space groups in column B can be skipped. However, none of the remaining magnetic space groups permits the magnetic moment to point along the $a$ or $b$ axis which gives rise to the $\left(\begin{array}{lll}0 & 0 & l\end{array}\right)$ reflections.
The neutron patterns of the $\operatorname{Pr}_{6} \mathrm{Fe}_{13} \mathrm{Sn}$ collected at $150 \mathrm{~K}$ was analyzed by employing the magnetic structure model of $\mathrm{Pr}_{6} \mathrm{Fe}_{13} \mathrm{Sn}$ proposed by Schobinger-Papamantellos et al. [11]. Fig. 3 shows the neutron diffraction pattern of the $\mathrm{Pr}_{6} \mathrm{Fe}_{13} \mathrm{Sn}$ recorded at $150 \mathrm{~K}$. The reliability factors are $R_{\mathrm{wp}}=9.5 \%$ and $R_{\mathrm{p}}=7.1 \%$ and $\chi^{2}=4.8$. It should be emphasized here that since the magnetic contribution is weak, the refined magnetic moments are imprecise. Within experimental error, the $\mathrm{Fe}$ sites have not reached the saturation value of 2.0(4) $\mu_{\mathrm{B}}$ at $150 \mathrm{~K}$. The respective magnetic moment values of Pr $8 f$ and $16 l$ sites are 2.1 (4) and 1.9 (4) $\mu_{\mathrm{B}}$. These values are below the magnetic moment of free $\operatorname{Pr}^{3+}$ ion value $g J=3.2 \mu_{\mathrm{B}}$. The refined crystal constants of $\mathrm{Pr}_{6} \mathrm{Fe}_{13} \mathrm{Sn}$ at $150 \mathrm{~K}$ are $a=8.1051(2) \AA$ and $c=23.4589$ (2) $\AA$ whereas the atomic positions and are presented in Table 3. As comparison, the refined atomic parameters at $1.5 \mathrm{~K}$ obtained by Schobinger-Papamantellos et al. [8] are listed in Table 4. It can be seen that the results of our neutron diffraction data and those of SchobingerPapamantellos et al. [8] are almost the same.

Table 3. Refined atomic parameters of $\operatorname{Pr}_{6} \mathrm{Fe}_{13} \mathrm{Sn}$ at $150 \mathrm{~K}$.

\begin{tabular}{|c|c|c|c|c|c|c|c|}
\hline Atom & site & $\begin{array}{c}\text { Point } \\
\text { symmetry }\end{array}$ & $\mu_{\mathrm{xy}}\left(\mu_{\mathrm{B}}\right)$ & $x$ & $y$ & $Z$ & $\begin{array}{c}\mathrm{Ui} / \mathrm{Ue}^{*} 100 \\
\left(\mathrm{~nm}^{2}\right)\end{array}$ \\
\hline Pr-1 & $8 f$ & 4 & $2.1(4)$ & 0 & 0 & $0.1060(4)$ & $0.99(3)$ \\
\hline Pr-2 & $16 l$ & $m$ & $1.9(4)$ & $0.1620(7)$ & $0.6620(7)$ & $0.1866(3)$ & $1.40(2)$ \\
\hline Fe-1 & $16 l_{1}$ & $m$ & $2.0(4)$ & $0.1798(3)$ & $0.6798(3)$ & $0.0587(2)$ & $0.72(3)$ \\
\hline $\mathrm{Fe}-2$ & $16 l_{2}$ & $m$ & $2.4(4)$ & $0.3868(3)$ & $0.8868(3)$ & $0.0939(2)$ & $0.69(5)$ \\
\hline Fe-3 & $16 k$ & $m$ & $2.0(4)$ & $0.0665(4)$ & $0.2097(4)$ & 0 & $0.64(2)$ \\
\hline $\mathrm{Fe}-4$ & $4 d$ & $\mathrm{mmm}$ & $2.0(4)$ & 0 & 0.5 & 0 & $0.27(3)$ \\
\hline Sn & $4 a$ & 422 & & 0 & 0 & 0.25 & $1.24(4)$ \\
\hline
\end{tabular}

Table 4. Refined atomic parameters of $\mathrm{Pr}_{6} \mathrm{Fe}_{13} \mathrm{Sn}$ at $1.5 \mathrm{~K}$ [8]

\begin{tabular}{clllllll}
\hline atom & site & \multicolumn{1}{c}{$x$} & \multicolumn{1}{c}{$y$} & \multicolumn{1}{c}{$z$} & \multicolumn{1}{c}{$\mu_{\mathrm{xy}}\left(\mu_{\mathrm{B}}\right)$} & \multicolumn{1}{c}{$\mathrm{B}\left(\mathrm{nm}^{2}\right) \times 10^{2}$} \\
\hline Pr-1 & $8 f$ & 0 & 0 & $0.1044(4)$ & $2.91(8)$ & $1.0(1)$ \\
$\mathrm{Pr}-2$ & $16 l$ & $0.1644(5)$ & $0.6644(5)$ & $0.1866(2)$ & $2.73(5)$ & $1.0(1)$ \\
$\mathrm{Fe}-1$ & $4 d$ & 0 & 0.5 & 0 & $2.3(2)$ & $0.18(3)$ \\
$\mathrm{Fe}-2$ & $16 k$ & $0.0655(3)$ & $0.2104(2)$ & 0 & $2.57(7)$ & $0.18(3)$ \\
$\mathrm{Fe}-3$ & $16 l_{1}$ & $0.1785(2)$ & $0.6784(2)$ & $0.0588(1)$ & $2.42(7)$ & $0.18(3)$ \\
$\mathrm{Fe}-4$ & $16 l_{2}$ & $0.3865(2)$ & $0.8865(2)$ & $0.0937(1)$ & $2.54(7)$ & $0.18(3)$ \\
$\mathrm{Sn}$ & $4 a$ & 0 & 0 & 0.25 & & $0.09(4)$ \\
\hline
\end{tabular}




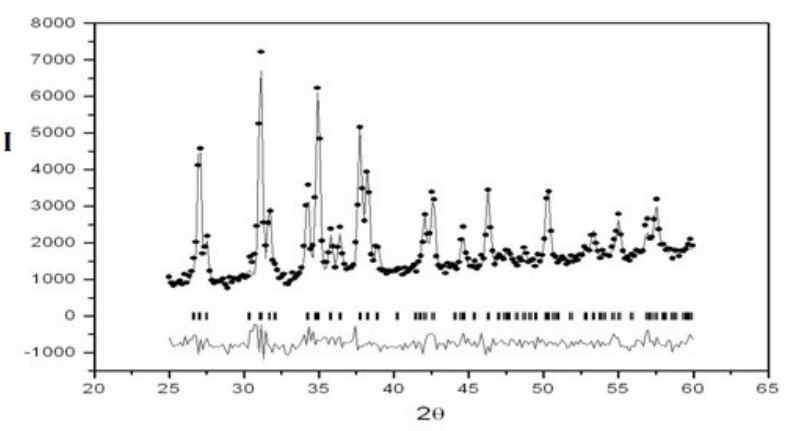

Fig. 1. The observed (dots), calculated (solid lines) and difference x-ray diffraction pattern of the $\mathrm{Pr}_{6} \mathrm{Fe}_{13} \mathrm{Sn}$ sample.

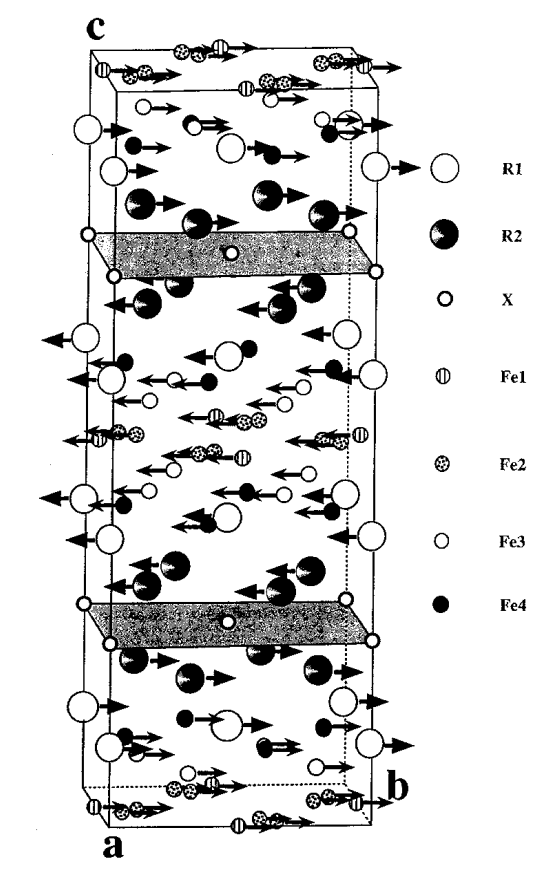

Fig. 2. Schematic representation of the antiferromagnetic structure of $\mathrm{Pr}_{6} \mathrm{Fe}_{13} \mathrm{Sn}$ [11]. In this work $\mathrm{R}=\mathrm{Pr}$, and $\mathrm{X}=\mathrm{Sn}$.

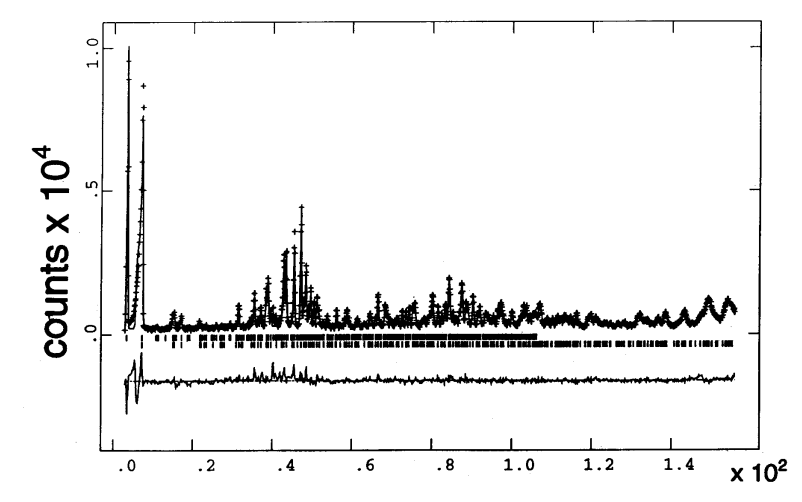

$2 \theta$

Fig. 3. Observed (crosses) and calculated (lines) neutron diffraction pattern of the $\operatorname{Pr}_{6} \mathrm{Fe}_{13} \mathrm{Sn}$ recorded $150 \mathrm{~K}$.

\section{CONCLUSIONS}

The Neutron diffraction work on the $\mathrm{Pr}_{6} \mathrm{Fe}_{13} \mathrm{Sn}$ has shown that the compound was antiferromagnetically ordered. The magnetic structure of $\mathrm{Pr}_{6} \mathrm{Fe}_{13} \mathrm{Sn}$ could be described as ferromagnetic blocks of parallel moments of $\mathrm{Pr}$ and $\mathrm{Fe}$ sublattices embedded between two successive Sn layers perpendicular to $\mathrm{z}$ located at $\mathrm{z}=0.25,0.25$ and 0.75 . The moments of these blocks changed their sign collectively when moved to the adjacent block along the c-axis. The refined $\mathrm{Pr}$ moments at $150 \mathrm{~K}$ were $(2.1 \pm 0.4)$ and $(1.9 \pm 0.4) \mu_{\mathrm{B}}$ for the $8 \mathrm{f}$ and $16 \mathrm{l}$ sites whereas the average of the Fe moments was $(2.0 \pm 0.4) \mu_{\mathrm{B}}$.

\section{ACKNOWLEDGEMENTS}

Suharyana would like to thank the AUSAid for the scholarship. This work partly was founded by. the Australian Research Grant.

\section{REFERENCES}

1. O.M. Sichevich, R.V. Lapunova, A.N. Soboley, Yu. N. Grin and Ya. P. Yarmulek, Sov. Phys. Crystallogr. 30 (1985) 627.

2. J. Allemand, A. Letant, J.M. Moreau, J.P. Nozires and R. Perrier de la Bâthie, J. Less-Common Met. 166 (1990) 73.

3. J. M. D. Coey, Q. Qi, K.G. Knoch, A. LeitheJasper and P. Rogl, J. Magn. Magn. Mater 129 (1994) 87.

4. F. Weitzer, A.A. Leithe-Jasper, P. Rogl, K. Hiebl, A. Rainbacher, G. Wiesinger, W. Steiner, J. Friedl and F.E. Wagner, J. Appl. Phys. 75 (1994) 7745.

5. Q.W. Yan, P.L. Zhang, X.D. Sun, B.P. Hu, Y.Z. Wang, X.L. Rao, G.C. Liu, C. Gou, D.F. Chen and Y.F. Cheng, J.Phys. : Condens. Matter 6 (1994) 3101.

6. T. Kajitani, K. Nagayama and T. Umeda, J. Magn. Magn. Mater 117 (1992) 379.

7. J.M. Cadogan and Suharyana, Hyperfine Interactions 123 (2001).

8. P. Schobinger-Papamentallos, K.H.J. Buschow, C. H. de Groot, F. R. de Boer and C. Ritter, J. Magn. Magn. Mater 31 (2000) 218. 
9. A.C. Larson and R.B. von Dreele, GSAS: General Structure Analysis System, Los Alamos National Laboratory, Los Alamos, NM 87545 (1994).

10. W Opechowski and $\mathrm{R}$ Guccione in Magnetism Vol IIA, edited by G.T. Rado and H. Suhl, Academic Press, New York (1965).

11. P. Schobinger-Papamentallos, K.H.J. Buschow, C.H. de Groot, F.R. de Boer, Böttger Grit and C. Ritter, J. Phys. :Condens. Matter 11 (1999) 4469. 
